\title{
Patógenos Involucrados en Casos Fatales de Diarrea en Crías de Alpaca de la Sierra Central del Perú
}

\author{
Pathogens Involved in Fatal Cases of Diarrhea in Young Alpacas in the \\ Central Highlands of Peru
}

\author{
Juan R. Lucas L. ${ }^{1,6,7}$, Siever Morales C. ${ }^{2}$, Manuel Barrios A. ${ }^{3}$, José Rodríguez G. ${ }^{1}$, \\ María Vásquez C. ${ }^{4}$, Boris Lira M. ${ }^{4}$, Bernardo Torres L. ${ }^{5}$, Eva Casas A. ${ }^{2}$, Juan \\ Espinoza B. ${ }^{5}$
}

\section{Resumen}

Se evaluó la presencia de enteropatógenos en 60 crías de alpacas de 1 a 2.5 meses de edad con cuadros mortales de diarrea de las regiones de Pasco y Junín, Perú. Se tomaron muestras de heces para determinar la frecuencia de Escherichia coli y Salmonella sp mediante microbiología convencional, de parásitos gastrointestinales por las técnicas de sedimentación y flotación, y de Criptosporidium sp mediante la técnica de Ziehl Neelsen modificado. Además, se evidenció la presencia de antígenos virales con la ayuda de un kit comercial de inmunocromatografía. Se identificó E. coli $(80 \%)$, coronavirus $(53.3 \%)$, Eimeria sp (43.3\%), Nematodirus sp (40\%), rotavirus (36.6\%), Criptosporidium sp (20\%) y Salmonella sp (18.3\%). Asimismo, se determinó que el $38.3 \%$ de los animales presentó los tres tipos de patógenos, mientras que el $23.3 \%$ presentó asociación de bacterias y parásitos, y el 11.7\% presentó asociación de virus y bacterias.

Palabras clave: alpacas, Criptosporidium sp, Eimeria sp, Escherichia coli, Salmonella sp

\footnotetext{
${ }^{1}$ Centro de Investigaciones IVITA, Estación El Mantaro, Facultad de Medicina Veterinaria, Universidad Nacional Mayor de San Marcos, Huancayo, Perú

${ }^{2}$ Laboratorio de Microbiología y Parasitología Veterinaria, ${ }^{3}$ Laboratorio de Patología Clínica y Biología Molecular, ${ }^{4}$ Laboratorio de Fisiología, ${ }^{5}$ Laboratorio de Farmacología y Toxicología, Facultad de Medicina Veterinaria, Universidad Nacional Mayor de San Marcos, Lima, Perú

${ }^{6}$ E-mail: jrlucas.pe@gmail.com

${ }^{7}$ El estudio fue financiado con fondos provenientes del Proyecto N. ${ }^{\circ} 173$ - FINCyT-IB-2013, Lima, Perú
} 
The presence of enteric pathogens was assessed in 60 young alpacas (1 to 2.5 months old) raised in Pasco and Junin, Peru that died due to diarrhea. Stool samples were collected to determine the frequency of Escherichia coli and Salmonella sp by conventional microbiology, gastrointestinal parasites by the sedimentation and flotation techniques, and Cryptosporidium sp by the modified Ziehl Neelsen technique. Besides, the presence of viral antigens using an immunochromatography commercial kit. The results showed the presence of $E$. coli (80\%), coronavirus (53.3\%), Eimeria sp (43.3\%), Nematodirus sp (40\%), rotavirus (36.6\%), Criptosporidium sp (20\%) and Salmonella sp (18.3\%). Moreover, it was determined that $38.3 \%$ of the animals presented the three types of pathogens, while $23.3 \%$ had association of bacteria and parasites, and $11.7 \%$ showed association of virus and bacteria.

Key words: alpaca, Criptosporidium sp, Eimeria sp, Escherichia coli, Salmonella sp

\section{INTRODUCCIÓN}

La alpaca es crucial en la seguridad alimentaria del poblador andino que habita por encima de los $3500 \mathrm{msnm}$, pues en muchos casos es su único medio de subsistencia. La alpaca suministra productos como fibra y carne a partir de los pastos pobres de las zonas altoandinas (Fernández Baca, 2005). El $85 \%$ de la producción alpaquera del Perú está en manos de comunidades campesinas y pequeños productores que viven en extrema pobreza y que no cuentan con el asesoramiento técnico adecuado (Bustinza et al., 1988; Amegino y De Martini, 1991).

Una de las principales limitantes en la crianza de alpacas es la elevada tasa de mortalidad en las crías, donde se observan frecuencias de 12 a $50 \%$, principalmente a causa de problemas diarreicos. Las diarreas neonatales en alpacas son causadas por enteropatógenos que incluyen principalmente bacterias, virus y parásitos (Bustinza et al., 1988; Amegino y De Martini, 1991; Whitehead y Anderson, 2006).

La región central de los Andes posee una importante población de alpacas, la cual se encuentra técnicamente desatendida des- de su repoblamiento en 1996, año en que el Ministerio de Agricultura del Perú movilizó alpacas a esta zona (Fernández Baca, 2005). El presente trabajo tuvo como objetivo identificar enteropatógenos en crías de alpacas de la sierra central peruana con cuadros fatales de diarrea.

\section{Materiales y Métodos}

\section{Lugar de Ejecución y Animales}

El estudio se realizó durante los meses de febrero y marzo de 2014 en las comunidades alpaqueras de Pasco y Junín, Perú, ubicadas por encima de los 3500 metros sobre el nivel del mar. Se evaluaron 60 alpacas, 42 machos y 18 hembras, de 1 a 2.5 meses de edad con cuadros fatales de diarrea.

Se realizó la necropsia de los animales afectados y se tomaron muestras de heces directamente del recto (aprox. $15 \mathrm{~g}$ ), para los análisis parasitológicos e identificación de antígenos virales. Para el análisis bacteriológico, las muestras de heces fueron recolectadas con hisopos estériles y colocadas en tubos con medio de transporte Stuart. Las muestras fueron llevadas en cajas térmicas $\left(4^{\circ} \mathrm{C}\right)$ al laboratorio de microbiología de la 
Universidad Científica del Sur, Lima, para los análisis bacteriológicos y virales y a los laboratorios de la Estación Experimental del Centro de Investigación IVITA de la Universidad Nacional Mayor de San Marcos, en El Mantaro, Junín, para los demás análisis.

\section{Análisis Parasitológico}

Las muestras fueron procesadas mediante los métodos cualitativos de sedimentación y flotación en solución saturada de azúcar y por el método cuantitativo de McMaster modificado para determinar la carga parasitaria e identificar las especies de parásitos (Hansen y Perry, 1994).

Se prepararon láminas teñidas con la coloración de Ziehl Neelsen modificado para detectar la presencia de Criptosporidium spp. Las muestras se observaron al microscopio con objetivos de 40-100X, considerándose positivas aquellas con la presencia de ooquistes del protozoario. Para esto, se tienen que visualizar organismos esféricos u ovalados de 4-6 $\mu \mathrm{m}$ de diámetro, de color rojo fucsia y con algunas granulaciones oscuras en su interior, que contrastaban con un fondo teñido de azul (Henricksen y Pohlenz, 1981). Se utilizó un microscopio óptico (Carl Zeiss) con cámara digital incorporada (AxionCam ERc5s, Carl Zeiss) y software de medición ZEN 2012 SP1 (Blue edition, Carl Zeiss).

\section{Análisis Bacteriológico e Identificación de Antígenos Virales}

Se realizó el aislamiento de Salmonella sp y Escherichia coli mediante protocolos convencionales (MINSA, 2005; OIE, 2008). La presencia de los antígenos virales de coronavirus y rotavirus se identificaron directamente de las heces mediante un kit comercial de inmunocromatografía en sandwich (Anigen Rapid BoviD-5 Ag Test Kit, Bionote), el cual detecta, además, antígenos de Criptosporidium y Escherichia coli k99.

\section{Resultados}

En la Figura 1 se muestra la frecuencia de patógenos en crías con diarrea. Se detectó al menos un tipo de virus, parásito o bacteria en el $60.0 \%$ (36/60), $73.3 \%(44 / 60)$ y $86.7 \%(52 / 60)$ de los animales, respectivamente. Asimismo, el 38.3\% (23/60) de los animales presentó los tres tipos de patógenos, mientras que el $23.3 \%$ (14/60) presentó asociación de bacterias y parásitos, y el $11.7 \%$ (7/60) de virus y bacterias.

E. coli fue el patógeno más frecuente $(80 \%, 48 / 60)$, estando como única causa aparente en el $10 \%$ (6/60) de las crías y asociado a Salmonella sp en el $13.3 \%$ (8/60). El coro-navirus estuvo presente en el 53.3\% (32/ 60 ) de las crías y asociado a rotavirus en el $30 \%$ (18/60). Eimeria sp fue el parásito más frecuente $(43.3 \%, 26 / 60)$, estando presente la asociación Nematodirus sp, Eimeria sp y Criptosporidium sp en dos casos (3.3\%).

El tamaño de las eimerias detectadas fue de 23-24 x 18-20 $\mu \mathrm{m}$ en E. alpacae, 81$107 \times 61-80 \mu \mathrm{m}$ en E. macusaniensis y de 30-40 x 21-30 $\mu \mathrm{m}$ en E. lamae. Las cargas parasitarias halladas se muestran en el Cuadro 1.

En las crías menores de 30 días de edad se detectaron principalmente, además de $E$. coli, a coronavirus y rotavirus, seguido de Eimeria sp, en tanto que en crías de 31 a 75 días de edad, después de $E$. coli, se detectó en mayor frecuencia al coronavirus, seguido de Eimeria sp y Nematodirus sp (Figura 1).

\section{Discusión}

Los enteropatógenos encontrados en el presente estudio y que han sido asociados a la diarrea neonatal en los camélidos sudamericanos (CSA) son los rotavirus, coronavirus, ciertas estirpes de Escherichia coli, Cyptosporidium sp y Coccidia (Rosadio y 


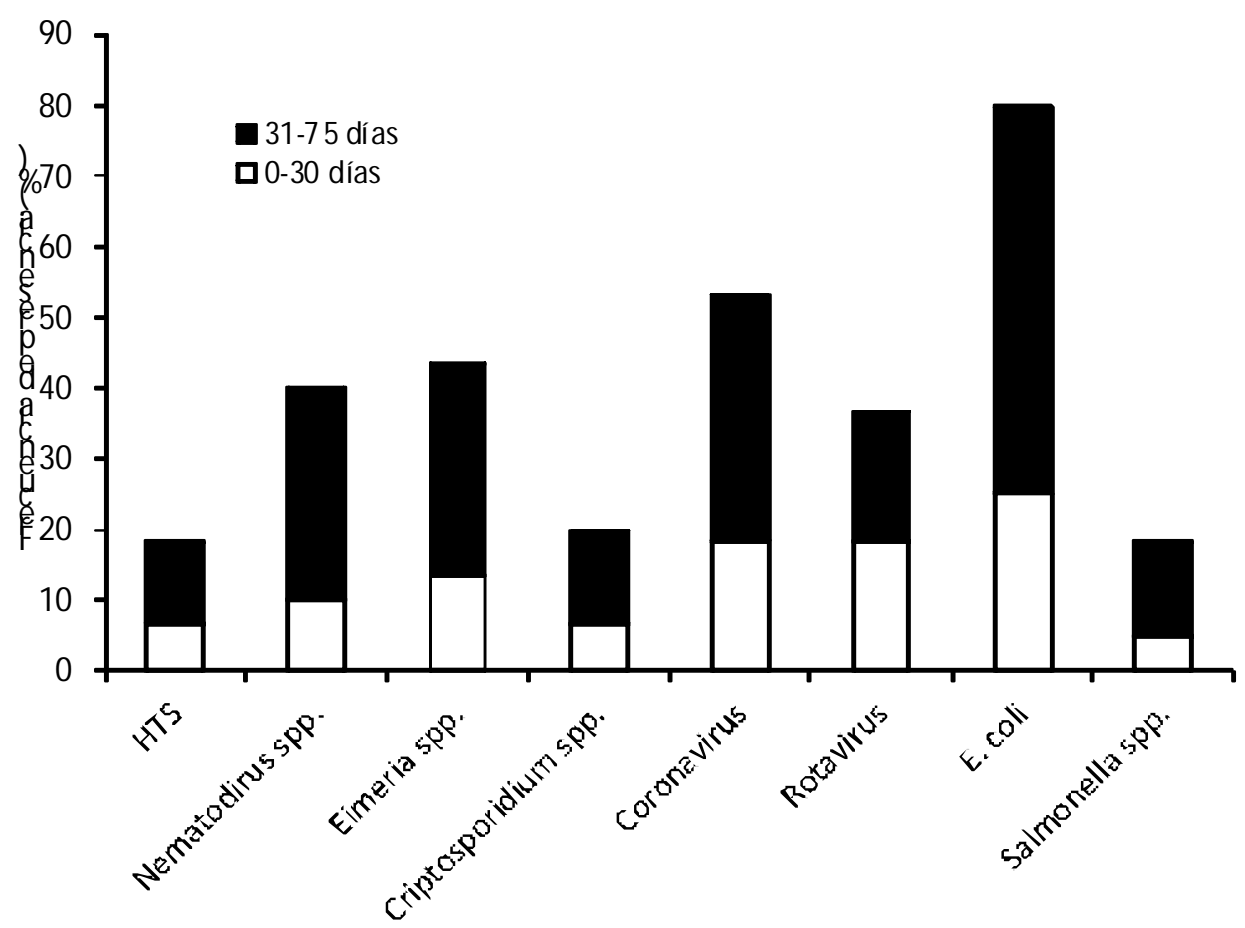

Figura 1. Frecuencia de causas de diarreas en crías de alpacas de la sierra central.

Cuadro 1. Promedio de huevos por gramo de heces (hpg) de parásitos en 60 crías de alpacas con diarrea en la sierra central del Perú

\begin{tabular}{lccc}
\hline \multirow{2}{*}{ Parásito } & Positivos & \multicolumn{2}{c}{ Huevos por gramo de heces (hpg) } \\
\cline { 2 - 4 } & $(\mathrm{n})$ & Promedio & Mínimo - Máximo \\
\hline Huevos tipo Strongylus & 11 & 73 & $0-400$ \\
Nematodirus sp & 24 & 329 & $50-1,500$ \\
Eimeria sp & 26 & 26779 & $50-253,800$ \\
Trichuris $\mathrm{sp}$ & 1 & 50 & - \\
\hline
\end{tabular}

Ameghino, 1994; Cebra et al., 2003; Whitehead y Anderson, 2006; Waitt et al., 2008).

El rotavirus de bovino ha demostrado ser causante de diarrea en crías de guanacos (Parreño et al., 2004). Asimismo, en el Perú, el $9.3 \%$ de crías de alpacas con cuadros diarreicos fueron identificados como positivas a rotavirus y, además, en asociación con E. coli (Morales et al., 2007), mientras que Cebra et al. (2003) los detectaron en el $2 \%$ de crías de llamas y alpacas con diarrea. En el presente trabajo, se encontró una frecuencia de rotavirus de $36.6 \%$, siendo mayor a los estudios previos.

Por otro lado, se conoce que el coronavirus bovino causa una severa enteritis viral en crías de alpaca (Cebra et al., 2003; Genova et al., 2008). Se ha establecido que es el agente causal del $40 \%$ de las diarreas en alpacas de 8-150 días de edad (Cebra et 
al., 2003; Whitehead y Anderson, 2006; Waitt et al., 2008), frecuencia similar a la reportada en el presente estudio.

Se han descrito varios parásitos protozoarios causantes de mortalidad en crías de alpacas, especialmente las eimerias (Rosadio y Ameghino, 1994; Cebra et al., 2003; Palacios et al., 2006; Whitehead y Anderson, 2006; Waitt et al., 2008). Así, Rosadio y Ameghino (1994) reportaron cuadros severos de diarrea en alpacas de 25-35 días, Cebra et al. (2003) aislaron este protozoo en el 13\% de crías con diarrea de 21 a 60 días de edad ,y Whitehead y Anderson (2006) la reportaron en el $12 \%$ en crías de 21 a 104 días. Esto es coincidente con los resultados presentados, donde la coccidiosis mostró una alta e importante frecuencia (Figura 1), especialmente en crías con más de 30 días de edad $(30 \%)$.

La carga parasitaria de Eimeria sp fue elevada (Cuadro 1), lo que implica que crías con cuadros diarreicos y positivas a coccidias pueden contaminar el ambiente en forma considerable. Los CSA se pueden infectar con Eimeria desde los primeros días de vida siempre que su entorno se encuentre muy contaminado. Asimismo, los cuadros severos se asocian con animales expuestos por primera vez al parásito y con una ingesta elevada de estas coccidias (Whitehead y Anderson, 2006).

Las eimerias de los CSA son altamente específicas, no pueden infectar a otros animales domésticos, pero puede existir la transmisión cruzada entre especies de CSA. Se ha reportado cinco especies que afectan a las alpacas: E. punoensis, E. ivitaensis, E. lamae, E. alpacae y E. macusaniensis (Palacios et al., 2006), donde las tres últimas fueron detectadas en el presente trabajo.

El 20\% (16/60) de las crías estuvieron infectadas con Criptosporidium sp, lo cual concuerda por López-Urbina et al. (2009) quienes reportaron $13 \%$ de prevalencia a nivel nacional y $12 \%$ para Junín. Asimismo,
Cebra et al. (2003) y Whitehead y Anderson (2006) reportan frecuencias de Criptosporidium de $9 \%$ en crías de alpaca de 10 a 45 días y de $26 \%$ en crías de 7 a 100 días de edad, respectivamente. Por otro lado, se indica que los casos fatales de criptosporidiasis ocurren mayormente en crías de 9 a 30 días de edad (Bidewell y Cattell, 1998; Waitt et al., 2008).

No se puede descartar que la parasitosis hallada (parásitos con huevos tipo Strongylus, Nematodirus sp y Trichuris sp) pueda contribuir al cuadro entérico, a pesar que la carga parasitaria haya sido relativamente baja (Cuadro 1). En los casos de teniasis y gastroenteritis verminosas en animales mayores de 2 meses se encuentra un gran número de huevos por gramo de heces (Whitehead y Anderson, 2006).

Salmonella sp fue aislada en el $18.3 \%$ de las alpacas y, si bien, reportes previos indican que esta bacteria no es una causa común de diarrea en alpacas (Cebra et al., 2003), se han detectado varias especies de Salmonella en animales menores de 6 meses de edad y con diarrea (Whitehead y Anderson, 2006).

En el caso de la colibacilosis, la infección ocurre como infección secundaria a otras enfermedades gastrointestinales, aunque también se le ha descrito en forma concomitante a infecciones por rotavirus o coronavirus, donde muestra una presentación más severa (Whitehead y Anderson, 2006). En el presente estudio, la asociación virus y bacterias se dio en el $11.7 \%$, donde E. coli K99 fue identificada en el $13.3 \%$ de los 60 casos, cifra importante que denota su participación en la diarrea neonatal.

Si bien $E$. coli es parte de la flora normal del tracto intestinal, existen cepas patógenas de este agente capaces de causar enfermedad en los animales y el hombre. $E$. coli fue la bacteria de mayor frecuencia en el presente estudio, por lo que es necesario determinar los patotipos existentes. E. coli 
enterohemorrágica y $E$. coli enteropatógena son patotipos que están involucrados en los cuadros diarreicos mortales en crías de alpacas en el Perú (Cid et al., 2011; Luna et al., 2012; Silvera et al., 2012).

\section{Literatura Citada}

1. Ameghino E, DeMartini J, 1991. Mortalidad de crías de alpacas. Bol Div IVITA, Lima. 71 p.

2. Bidewell C, Catell J. 1998. Cryptosporidiosis in young alpacas. Vet Rec 142: 287.

3. Bustinza AV, Burfening PJ, Blackwell $\boldsymbol{R L}$. 1988. Factors affecting survival in young alpacas (Lama pacos). J Anim Sci 66: 1139-1143.

4. Cebra C, Mattson D, Baker R, Sonn $R$, Dearing P. 2003. Potential pathogens in feces from unweaned llamas and alpacas with diarrhea. J Am Vet Med Assoc 223: 1806-1808. doi: 10.2460/ javma.2003.223.1806

5. Cid D, Martín-Espada C, Maturrano L, García A, Luna L, Rosadio $R$. 2011. Diarrheagenic Escherichia coli strains isolated from young Peruvian alpacas (Vicugna pacos) with diarrea. En: Perez-Cabal MA, Gutierrez JP, Cervantes I, Alcalde MJ (eds). Fibre production in South American camelids and other fibre animals. The Netherlands: Wageningen Academic Publishers. p 223-228. doi: 10.3920/978-90-8686-727-1

6. Fernández Baca S. 2005. Situación actual de los camélidos sudamericanos en Perú. Santiago de Chile: Organización de las Naciones Unidas para la Agricultura y la Alimentación (FAO). 63 p.

7. Genova SG, Streeter RN, Simpson KM, Kapil S. 2008. Detection of an antigenic group 2 coronavirus in an adult alpaca with enteritis. Clin Vaccine Immunol 15: 1629-1632. doi: 10.1128/CVI.00232-08

8. Hansen J, Perry B. 1994. The epidemiology, diagnosis and control of helminth parasites of ruminants. $2^{\text {nd }} \mathrm{ed}$.
Nairobi, Kenya: International Laboratory for Research on Animal Diseases. $171 \mathrm{p}$.

9. Henricksen SA, Pohlenz JFL. 1981. Staining of Cryptosporidium by a modified Ziehl-Neelsen technique. Acta Vet Scand 22: 594-596.

10. López-Urbina MT, González AE, Gomez-Puerta LA, Romero-Arbizu MA, Perales-Camacho RA, RojoVázquez FA, Xiao L, Cama V. 2009. Prevalence of neonatal cryptosporidiosis in Andean alpacas (Vicugna pacos) in Peru. Open Parasitol J 3: 9-13.

11. Luna L, Maturrano L, Rivera $H$, Zanabria V, Rosadio R. 2012. Genotipificación, evaluación toxigénica in vitro y sensibilidad a antibióticos de cepas de Escherichia coli aisladas de casos diarreicos y fatales en alpacas neonatas. Rev Inv Vet Perú 23: 280-288. doi: 10.15381/rivep.v23i3.910

12. [MINSA] Ministerio de Salud del Perú. 2005. Manual de procedimientos bacteriológicos en infecciones intrahospitalarias. Lima: CEPREDIM. Serie de Normas Técnicas No 28. 106 p.

13. Morales S, Paredes S, Pezo D. 2007. Asociación de rotavirus y Escherichia coli fimbriada como agentes causales de infecciones entéricas en alpacas neonatas. Rev Inv Vet Perú 18: 150-153. doi: 10.15381/rivep.v18i2.1486

14. [OIE] Organización Mundial de Sanidad Animal. 2008. Cap 2.9.9. Salmonelosis. En: Manual de las pruebas de diagnóstico y de las vacunas para los animales terrestres. $6^{\mathrm{a}}$ ed. Paris: OIE. p 1268-1286.

15. Palacios CA, Perales RA, Chavera AE, Lopez MT, Braga WU, Moro M. 2006. Eimeria macusaniensis and Eimeria ivitaensis coinfection in fatal cases of diarrhoea in young alpacas (Lama pacos) in Peru. Vet Rec 158: 344-345.

16. Parreño V, Bok K, Fernandez F, Gomez J. 2004. Molecular characterization of the first isolation of rotavirus in guanacos (Lama guanicoe). Arch Virol 149: 2465-2471. doi: 10.1007/ s00705-004-0371-2 
17. Rosadio RH, Ameghino EF. 1994. Coccidial infections in neonatal Peruvian alpacas. Vet Rec 135: 459-460. doi: 10.1136/vr.135.19.459

18. Silvera E, Perales R, Rodríguez J, López T, Gavidia C, Agapito J, Palacios C. 2012. Presencia de Escherichia coli $\mathrm{O} 157$ en crías de alpacas (Vicugna pacos). Rev Inv Vet Perú 23: 98-104. doi: 10.15381/rivep.v23i1.888
19. Waitt LH, Cebra CK, Firshman AM, McKenzie EC, Schlipf JW Jr. 2008.

Cryptosporidiosis in 20 alpaca crias. J Am Vet Med Assoc 233: 294-298. doi: 10.2460/javma.233.2.294

20. Whitehead C, Anderson D. 2006. Neonatal diarrhea in llamas and alpacas. Small Ruminant Res 61: 207-215. doi: 10.1016/j.smallrumres.2005.07.012 